MIRKO ČORIĆ, M.Eng.

(Corresponding author)

E-mail: mcoric@pfst.hr

ANITA GUDELJ, Ph.D.

E-mail: anita@pfst.hr

ZVONIMIR LUŠIĆ, Ph.D.

E-mail: zlusic@pfst.hr

University of Split, Faculty of Maritime Studies

Ruđera Boškovića 37, HR-21000 Split, Croatia
Information and Communication Technology

Preliminary Communication

Submitted: Dec. 23, 2014

Accepted: Feb. 2, 2016

\title{
CLASSIFIED VECTOR QUANTIZATION AND ITS APPLICATION ON COMPRESSION OF IRIS IMAGES IN THE SAFETY OF MARINE SYSTEMS
}

\begin{abstract}
As a standard, 512 byte IrisCode templates developed with specific algorithms are stored in databases and used in iris recognition process. Future tendencies are to use exclusively real iris images rather than IrisCode templates in the iris recognition process. Many of current iris recognition systems use portable devices (e.g. iris scanners) which are often required to transmit image or template over communication channel. Image compression can be used in order to reduce the transmission time and storage capacities. Classified Vector Quantization (CVQ) and ordinary Vector Quantization (VQ) are used for compression of greyscale iris images collected from one of the available public databases of iris images. Results show that both compression methods are significantly more effective when applied to iris images than when applied to average images from everyday environments since iris images are fairly uniform and contain low contrast levels. Originally, CVQ is used to improve the quality of edges of compressed images because they are the most important part of image for visual impression on humans. The paper presents the comparison and major advantage of CVQ over ordinary VQ in terms of significant time reduction needed for iris images to be coded, and therefore it highlights a new important application of CVQ.
\end{abstract}

\section{KEY WORDS}

iris recognition; marine security; classified vector quantization;

\section{INTRODUCTION}

Iris recognition is a method of identifying people based on unique patterns within the ring-shaped region surrounding the pupil of the eye [1]. It has been shown that the iris biometrics has major advantages over other biometrics, and is considered to be the most reliable method for human identification [1]. It is most often used for security-related applications. Due to the increased terrorist attacks and trespasses, biometric technology has become a viable solution for port and ship security, and it is already adopted in other areas of transport sector. Also, seaports and marine terminals are home to high consequence facilities such as oil and gas storage, chemical, intermodal and port operations. These kinds of environments require accurate and reliable access control and identity verification which can be obtained via iris recognition system.

Iris identification procedure includes enrolment of a person into a commercial iris system, generally requiring several IrisCode templates derived from iris images of a person to be taken and stored in a database. In most of the cases, these databases do not contain actual iris images, but 512 byte binary files containing distinctive information of each and every enrolled iris (called IrisCode templates). IrisCode templates are created from the standard greyscale iris images of $640 \times 480$ pixels format. The majority of the commercial iris systems use Daugmans algorithm to create IrisCode templates from iris images [1, 2]. Logically, desirable upgrade would be the use of real iris images instead of templates in order to avoid all the intermediate steps that generate IrisCode templates. Moreover, different policies even require that biometric data should be stored in image form, rather than in the form of templates created with specific algorithms in order to achieve interoperability and vendor neutrality [3]. Also, the usage of portable iris recognition systems that often require data transfer over communication channel is increasing, e.g. Coast Guard is using them so they can rapidly identify suspected migrants or smugglers at sea [4]. In this and in many other cases, data transmission, thus the identification process should be as fast as possible. The solution to all these issues is the usage of compressed real iris images instead of templates while maintaining accuracy and reliability in the recognition procedure. It has been already experimentally proved that this solution is 
possible, meaning that compression of real iris images can have negligible impact on the recognition accuracy if applied under certain circumstances [5, 6]. Previous experiments also show that vector quantization gives better results than Discrete Cosine Transform (DCT) method $[7,8]$ which is already accepted as a standard in the majority of video and image compression methods [9, 10, 11].

This paper puts emphasis primarily on Classified Vector Quantization (CVQ) [12] where the classification is based on edges, and its application on compression of iris images. CVQ uses training set of vectors extracted from training set of images in order to generate codebooks.

Codebooks contain approximation blocks of pixels (vectors) that are used to replace blocks of pixels from original images that are ready to be coded. In order to get better results, the training set of images should contain maximum possible number of blocks of pixels that correspond to the blocks from original images that will be coded. Generally, the results of coding will be better as the similarity is greater between the training set of images and the images that will be coded. Iris images are fairly uniform in grey level and the contrast levels within the iris area are very low from the perspective of image processing. Therefore, this paper explores whether there are advantages of this method when applied to the compression of iris images over average images from other environments, and most importantly, it investigates the advantages of CVQ over ordinary VQ method, particularly in terms of time reduction of the iris image compression process. The next Section describes the potential of iris recognition method used in shipping and port business/industry. Third Section refers to a special algorithm used for edge classification within the CVQ, called comparison of locally thresholded image vectors with a predefined set of binary edge templates [13], which is used in this paper. Methodology, results and discussion are given in the fourth Section.

\section{IRIS RECOGNITION AS A BIOMETRIC METHOD IN PORT AND SHIPPING SECURITY}

Port and shipping security is a risk management activity and in the business of security the risk management process begins with understanding the target environment as being fraught with risks that must be identified, assessed and managed (e.g. ports are interesting targets for terrorist and criminal conspiracies due to their high role in national and local economies). Therefore, development of comprehensive and reliable security systems is important. Biometric recognition has emerged as one of the key elements in security against terrorism threat, as well as in subject identification and prevention of unauthorized access in general. Iris recognition provides one of the most secure methods of authentication and identification [1, 2]. One of the extensive studies conducted in the USA showed that iris biometrics should be taken seriously into consideration as the primary identification method because of its accuracy and the nature of marine systems [14]. Iris scanning as a "stand-off" biometrics includes no physical contact between the subject and the iris scanning device, which may not be negligible in marine environments such as ports and ships. Iris biometrics is highly superior when compared to other "stand-off" biometric methods (e.g. facial and gait recognition) [15]. Also, widespread fingerprint recognition method may experience some issues in marine environments (subjects must make physical contact with fingerprint scanner e.g. the subject must leave the vehicle in order to access fingerprint scanner, subjects working in wet marine environments sometimes may experience a common side effect: wrinkled or shrivelled fingers, etc.). Iris biometrics is the most promising one in the set of technologies that allow an iris scanner to acquire the iris scan of a subject at a considerably greater distance than the conventional iris scanners. Some studies show the potential of scanning the subject at up to one meter even if the subject is moving $[16,17]$.

Iris scanning is used in various scenarios around the world and they are mostly implemented in office-like environments where the environmental conditions are fairly stable. Portable iris scanners are suitable for applications that require the iris scanners to be mobile. These devices are more suited for outdoor environments and environments where there is less control over conditions (humidity, weather conditions, sunlight, etc.) in general. Marine systems, such as ports, marine terminals, ships etc. can often be regarded as such. Portable iris scanners PIER 2.3. were used in research that was carried out within the marine system, and satisfying results were obtained [14]. If properly implemented, iris scanning can drastically improve the accuracy of identification of port/ ship workers and other subjects in security sensitive positions. Minimization of the time required to carry out the identification procedure on a daily basis is of great importance as well [18].

\section{CLASSIFICATION OF EDGES USING COMPARISON OF LOCALLY THRESHOLDED IMAGE VECTORS WITH A PREDEFINED SET OF BINARY EDGE TEMPLATES}

CVQ is an advanced method of ordinary VQ [12]. There are many different properties that can be considered during classification. Generally, when it comes to image, classification is based on edges. The de- 
scription of the algorithm used in this paper for edge classification is as follows:

In this method, the first step is the decision about whether the image vector is edge or non-edge. Therefore, each grey pixel $g(i, j)$ is assigned the weighting factor $w(i, j)$ which is calculated using the horizontal $\left(e_{h}\right)$ and vertical $\left(e_{v}\right)$ gradient, and two diagonal gradients $\left(e_{d 1}, e_{d 2}\right)$, based on the neighbouring pixels. Gradients and weighting factor can be estimated as:

$$
\begin{aligned}
& e_{h}= \max (|g(i, j)-g(i+1, j)|,|g(i, j)-(i-1, j)|) \\
& e_{v}= \max (|g(i, j)-g(i+1, j)|,|g(i, j)-(i, j-1)|) \\
& e_{d 1}= \max (|g(i, j)-g(i+1, j+1)|, \\
&|g(i, j)-(i-1, j-1)|) \\
& e_{d 2}= \max (|g(i, j)-g(i-1, j+1)|, \\
&|g(i, j)-(i+1, j-1)|) \\
& w(i, j)=\max \left(e_{h}, e_{v}, e_{d 1}, e_{d 2}\right)
\end{aligned}
$$

If any of the weight factors $w(i, j)$ is greater than a predetermined threshold $T_{s}$, then the image vector is considered to be an edge, otherwise it is considered to be a non-edge. The next step is binarization of the edge vectors based on threshold $T$. Edge vectors are vectors that contain at least one weighting factor larger than threshold $T_{s}$. Binarization is done in a way that pixels of the grey image are compared with the predetermined threshold $T$. Depending on the value of threshold $T$, pixels are converted to full-black or fullwhite colour. Using this method, grey images that contain pixels of value $g(i, j)$ are transformed to black and white images that contain pixels of value $g_{B W}(i, j)$, so the expression is:

$g_{b w}=(i, j)= \begin{cases}0, & g(i, j) \leq T \\ 255, g(i, j)>T\end{cases}$

which refers to the black and white images with values ranging from 0 to 255 ( 0 is the black colour, and 255 is the white colour). Threshold value $T$ for the vector of size $4 \times 4$ is calculated as:

$$
\begin{aligned}
& T=\sum_{i=1}^{4} \sum_{j=1}^{4} \frac{w(i, j)}{W} g(i, j) \\
& W=\sum_{i=1}^{4} \sum_{j=1}^{4} w(i, j)
\end{aligned}
$$

Binarized vectors are classified in a way that they are compared with fixed patterns that correspond to the most common vectors with vertical, horizontal and diagonal orientation. It is necessary to calculate the distance (number of different pixels between binarized vector and fixed pattern) for all the patterns. If the smallest of these distances is greater than threshold $T_{M}$, then the vector is considered to be a mixed class. If the smallest of these distances is less than threshold $T_{M}$, then the vector is classified as the class for which the distance is the smallest, i.e. as one of the 28 classes shown in Figure 1.

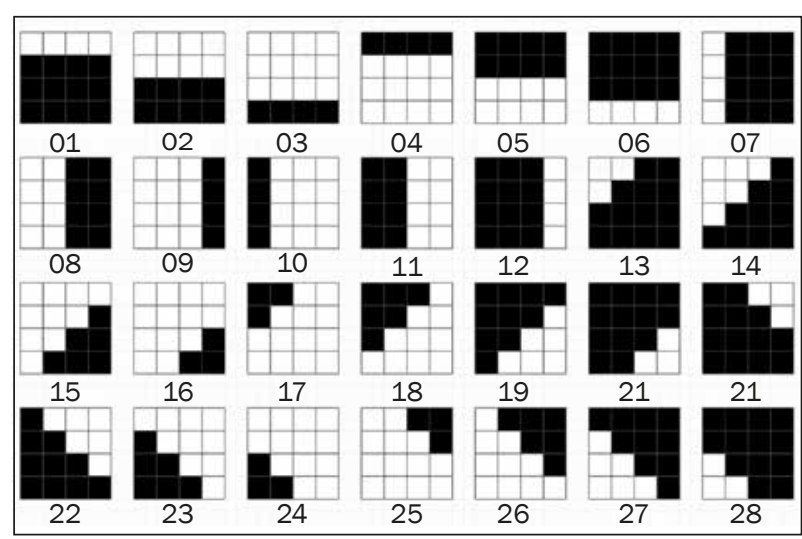

Figure 1 - Fixed edge patterns

Source: Quweider, M. K., and E. Salari. "Efficient classification and codebook design for CVQ." IEE Proceedings-Vision, Image and Signal Processing 143.6 (1996): 344-352.

Therefore, each vector can be classified as edge or non-edge. Edge is further classified as one of the 28 classes or as a mixed class. Mixed class contains a lot of complex edge patterns, such as edges in the form of letter $\mathrm{O}, \mathrm{L}, \mathrm{U}$ and many other forms. It was experimentally determined that images of intensity between 0 and 255 have threshold values $T_{M}=3$ and $T_{s}=19$.

\section{METHODOLOGY AND EXPERIMENTAL RESULTS}

\subsection{Methodology}

In order to perform the experiment, two test cases were analyzed, and their results compared. For the first test case, nine random grey iris images from Phoenix iris database [19] were taken as a training set of input images (Figure 2).

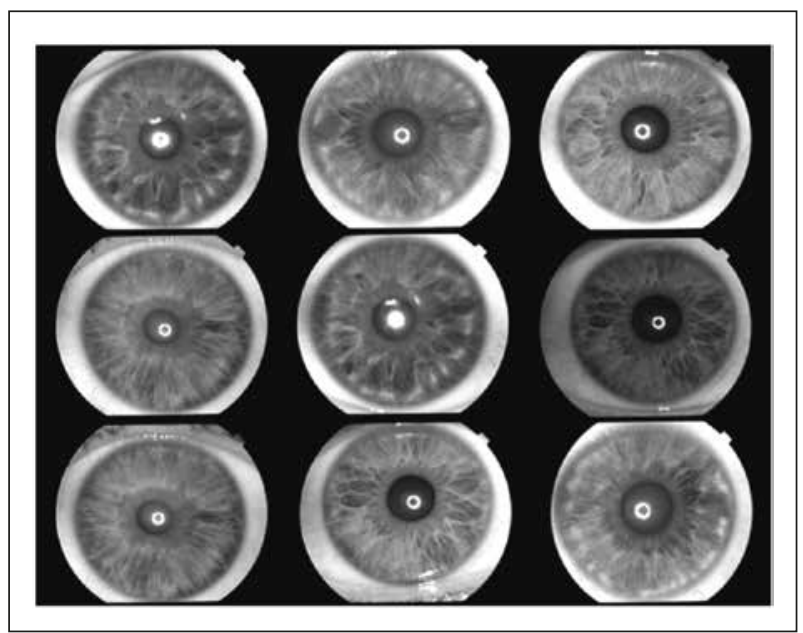

Figure 2 - Training images of the first test case

Source: http://phoenix.inf.upol.cz/iris/

Original images from the database were $768 \times 576$ pixels. It was necessary to crop them in order to get the 
standard size of $640 \times 480$ pixels. No other preprocessing of images has been done. The considered size of each block of pixels (vector) was $4 \times 4$ pixels. Therefore, each of these nine images contained 19,200 training vectors, meaning that all nine images contained 172,800 training vectors. Training vectors were extracted from these images, and classified afterwards. Pattern comparison algorithm was used for classification of training vectors. In other words, extracted vectors were distributed among 30 different classes. Twenty-eight classes refer to fixed edge patterns (See Figure 1), and other two classes are mixed class (containing all the edges that do not belong to any of the 28 classes) and a non-edge class (containing every vector that is not considered to be an edge). Separate codebooks of different sizes $(64,32,16,8,4$ codewords) were created for each class of training vectors. LBG algorithm [20] was used to create codebooks.

In the second test case, 18 grey images from average environments were taken as a training set of input images (Figure 3).

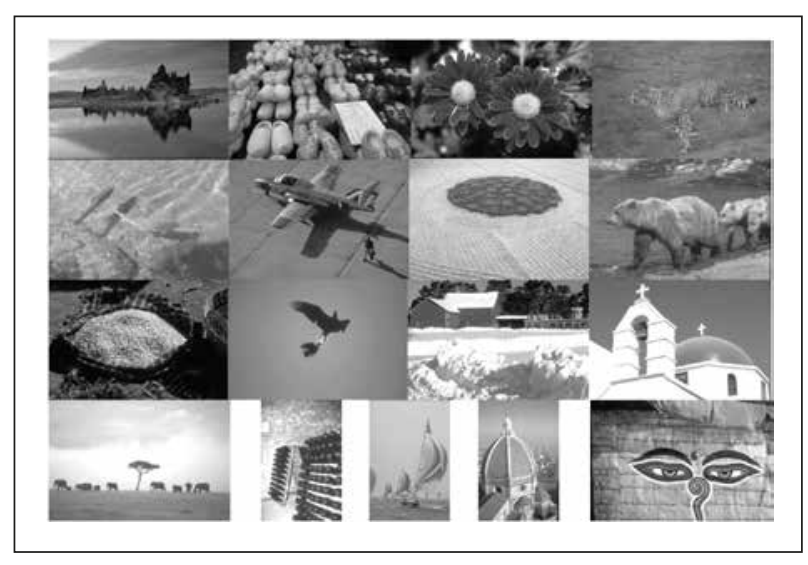

Figure 3 - Training images of the second test case

Images were selected so as to better represent all possible inputs from the average environments (images were not homogeneous, but diverse). Fifteen images were the size of $480 \times 320$ pixels, while three images were the size of $320 \times 480$ pixels. The considered size of each vector was $4 \times 4$ pixels which is same as in the first test case. Each of 18 images contained 9,600 training vectors, therefore all 18 images contained 172,800 training vectors which is also the same as in the first test case. Exactly the same procedure (extraction, classification and generation of codebooks for each class with LBG algorithm) as in the first test case was performed.

Finally, the codebooks of different sizes, for each and every class and for both test cases were obtained. Therefore, input vectors from original images can be coded at different bit rates using CVQ. In order to compare the performances between CVQ and ordinary VQ, codebooks for ordinary VQ were generated as well (using LBG algorithm). In other words, all 172,800 training vectors from the first test were used to generate codebooks of size 2,048, 1,024, 512, 256 and 128 codewords for that particular test case. Also, a total of 172,800 training vectors from the second test case were used to generate codebooks of the same size for that particular test case. Codebook sizes were selected in such a way that CVQ and VQ can be performed at the same bit rate. For the first test case, three grey iris images from Phoenix database were coded via CVQ and VQ. In the second test case, three grey average images (lena, ship and pepper) were coded via CVQ and VQ as well. The coding was performed using the same bit rate levels (range from $0.43-0.68$ bits per pixel) for both test cases. Coding of three images for each test case was performed using codebooks that were generated particularly for that test case. Mean Squared Error (MSE) [21] was used as a measure of the quality of coding. Complete methodology was performed in Matlab 7.7 using several Matlab scripts specially designed for this purpose.

\subsection{Results and discussion}

Coding results for both test cases are shown in Table 1 and Table 2.

First positive effect of VQ and CVQ applied on iris image compression is as follows: results show that coded iris images from the first test case (see Table 1) are of significantly better quality (smaller MSE) than coded images from the second test case (see Table 2), at the same bit rate levels. It means that iris images

Table 1 - Coding results for the first test case

\begin{tabular}{|c|c|c|c|c|c|c|c|c|c|c|c|c|}
\hline \multirow{3}{*}{$\mathrm{bpp}$} & \multicolumn{6}{|c|}{ VQ } & \multicolumn{6}{|c|}{ CVQ } \\
\hline & \multicolumn{2}{|c|}{ Iris 1} & \multicolumn{2}{|c|}{ Iris 2} & \multicolumn{2}{|c|}{ Iris 3} & \multicolumn{2}{|c|}{ Iris 1} & \multicolumn{2}{|c|}{ Iris 2} & \multicolumn{2}{|c|}{ Iris 3} \\
\hline & MSE & $\begin{array}{l}\text { coding } \\
\text { time(s) }\end{array}$ & MSE & $\begin{array}{l}\text { coding } \\
\text { time(s) }\end{array}$ & MSE & $\begin{array}{l}\text { coding } \\
\text { time(s) }\end{array}$ & MSE & $\begin{array}{l}\text { coding } \\
\text { time(s) }\end{array}$ & MSE & $\begin{array}{c}\text { coding } \\
\text { time(s) }\end{array}$ & MSE & $\begin{array}{l}\text { coding } \\
\text { time(s) }\end{array}$ \\
\hline 0.437 & 17.74 & 13.18 & 14.29 & 13.02 & 15.60 & 12.62 & 38.81 & 0.39 & 32.19 & 0.39 & 31.30 & 0.39 \\
\hline 0.5 & 12.44 & 24.92 & 10.19 & 24.35 & 11.74 & 23.95 & 21.42 & 0.74 & 19.78 & 0.73 & 20.79 & 0.74 \\
\hline 0.562 & 9.11 & 48.43 & 8.26 & 46.13 & 9.01 & 46.49 & 12.54 & 1.44 & 10.87 & 1.45 & 12.23 & 1.45 \\
\hline 0.625 & 7.39 & 94.70 & 6.55 & 92.15 & 7.22 & 90.61 & 7.71 & 2.82 & 6.32 & 2.83 & 7.48 & 2.83 \\
\hline 0.687 & 5.86 & 188.56 & 5.43 & 180.04 & 5.90 & 183.01 & 6.22 & 5.66 & 5.19 & 5.63 & 6.05 & 5.60 \\
\hline
\end{tabular}


Table 2 - Coding results for the second test case

\begin{tabular}{||c|c|c|c|c|c|c||}
\hline \multirow{2}{*}{ bpp } & \multicolumn{3}{|c|}{ VQ } & \multicolumn{3}{c||}{ CVQ } \\
\cline { 2 - 7 } & lena (MSE) & ship (MSE) & pepper(MSE) & lena (MSE) & ship (MSE) & pepper(MSE) \\
\hline \hline 0.437 & 39.52 & 57.22 & 40.98 & 62.99 & 93.10 & 64.07 \\
\hline 0.5 & 33.10 & 50.00 & 35.24 & 46.19 & 61.21 & 50.98 \\
\hline 0.562 & 28.51 & 44.20 & 30.62 & 29.99 & 51.12 & 33.25 \\
\hline 0.625 & 25.63 & 39.77 & 26.95 & 24.94 & 40.96 & 27.32 \\
\hline 0.687 & 19.81 & 35.72 & 22.05 & 19.67 & 36.13 & 22.18 \\
\hline
\end{tabular}

are more suitable candidates for VQ and CVQ than images from the average environments. We attribute this to the fact that iris images are less diverse and more homogeneous than images from Figure $3[22,23]$. Ordinary VQ gives better results at lower bit rate levels, while the results from VQ and CVQ are approximately the same or slightly in favour of VQ at higher bit rate levels (0.625 bpp and above). Average MSE of iris images from the first test case coded via CVQ and VQ (see Table 1) is shown in Figure 4.

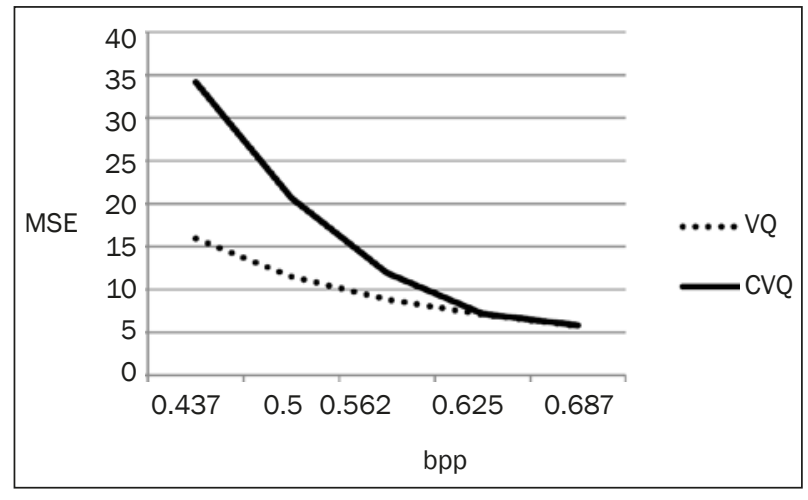

Figure 4 - Average MSE of coded iris images from Table 1 using CVQ and VQ at different bit rate levels

It is not desirable to code iris images at very low bit rate levels due to significant degradation in iris image quality (higher MSE). Therefore, higher bit rate levels are of particular interest for coding of iris images. Coded data are actually simple indexes that point to corresponding representative blocks of data contained in the codebook. In VQ and CVQ the amount of coded data which is stored or sent over communication channel is the same for all bit rate levels. There is all the more reason to use higher bit rate levels (lower MSE) to code iris images. The coding time for all three iris images from the first test case is shown in Table 1 as well. Obviously, the main advantage of CVQ over ordinary $\mathrm{VQ}$ in iris recognition process refers to a significant reduction in the time required for iris image coding. The coding time affects directly the time required to perform overall iris recognition process. This advantage is greater at higher bit rate levels. The average time required to code iris images from the first test case (see Table 1) via CVQ and ordinary VQ at different bit rate levels is shown in Figure 5.

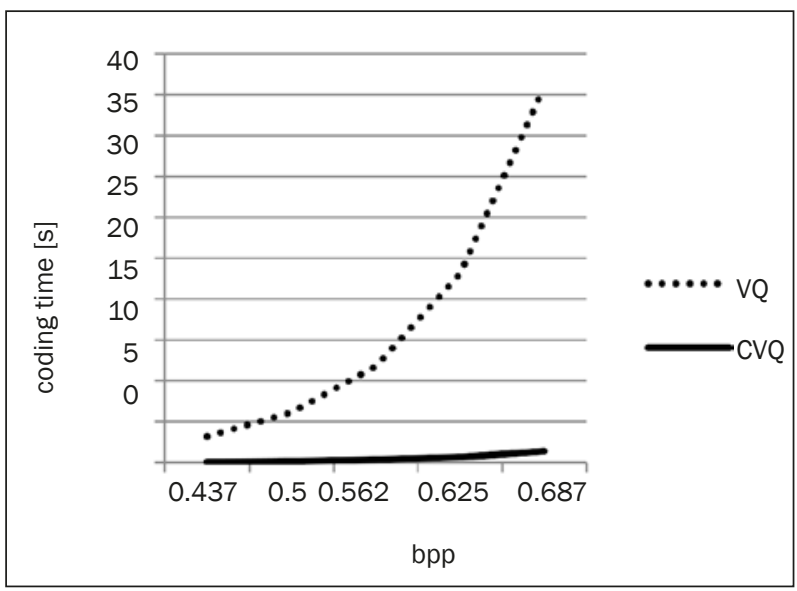

Figure 5 - Average time needed to code iris images from Table 1 at different bit rate levels via CVQ and VQ

Coding time grows exponentially as the number of bits used for coding increases in the case of ordinary VQ. Computational complexity in terms of generating codebooks at higher bit rate levels is not an issue because the same codebook once generated can be used all the time for each and every iris recognition procedure. Moreover, CVQ solves the problem of searching for the closest codeword within large codebooks at higher bit rate levels. All the tests were performed on Intel Core i5 processor $(2.50 \mathrm{GHz}), 4 \mathrm{~GB}$ RAM on Windows 7.

\section{CONCLUSION}

Previously performed experiments from other studies proved that ordinary VQ provides better results than DCT method when used for iris image compression. This paper expands the issue, and points out a new application of CVQ. Results show that CVQ has a significant coding time advantage over VQ which can be of great importance when used in iris recognition procedures. Both methods give significantly better results when applied to standard greyscale iris images used for biometric identification than when applied to average images from everyday environments. The reason lies in the fact that the iris images are fairly uniform and images contain low contrast levels. Higher bit rate levels are of particular interest for the iris image 
compression due to iris image quality importance, and the results obtained via CVQ and VQ are approximately the same at these levels. Iris recognition process should be as fast as possible. It means that a person who has entered the iris recognition procedure should wait as little as possible for the identification process to be executed, which is of great importance for the majority of iris biometric applications within different marine security systems. The results show that compression of irises via proposed CVQ brings significant time decrease in the process of image coding which directly affects the time required to perform overall iris recognition procedure. Although the main motivation for this research is marine security, benefits are fully applicable for the safety of other systems, such as airport and air traffic security, road transport security, border security, i.e. in every area that requires identification. Future research will focus on further shortening of coding time of iris images, and further quality increase of coded images using general image processing techniques.

MIRKO ĆORIĆ, Mag.ing.

E-mail: mcoric@pfst.hr

Dr. sc. ANITA GUDELJ

Zrinsko-Frankopanska 38, 21000 Split, Hrvatska

Dr. sc. ZVONIMIR LUŠIĆ

E-mail: zlusic@pfst.hr

Sveučilište u Splitu, Pomorski fakultet

Zrinsko-Frankopanska 38, 21000 Split, Hrvatska

\section{VEKTORSKA KVANTIZACIJA S KLASIFIKACIJOM I NJENA PRIMJENA NA KOMPRESIJU SLIKA MREŽNICA U SIGURNOSTI POMORSKIH SUSTAVA}

\section{SAŽETAK}

Kao standard, specijalnim algoritmima dobiveni IrisCode predlošci od 512 bajtova pohranjuju se u baze podataka te se koriste u postupcima prepoznavanja putem mrežnica. Buduće tendencije nalažu upotrebu isključivo stvarnih slika mrežnica umjesto IrisCode predložaka u postupcima prepoznavanja putem mrežnica. Mnogi od trenutnih sustava za prepoznavanje koriste prijenosne uređaje (npr. skenere mrežnica) koji često trebaju slati sliku ili predložak preko komunikacijskog kanala. Kompresija slike se može koristiti u svrhu smanjenja vremena prijenosa slike i skladišnih kapaciteta. Vektorska Kvantizacija s Klasifikacijom (CVQ) i obična Vektorska Kvantizacija (VQ) su korištene za kompresiju sivih slika mrežnica koje su prikupljene iz jedne od dostupnih javnih baza podataka mrežnica. Rezultati pokazuju da su obje metode značajno djelotvornije kada se primjene na prosječne slike iz svakodnevnih okoliša, budući da su slike mrežnica prilično ujednačene $i$ sadrže niske razine kontrasta. Izvorno se CVQ koristi kako bi se poboljšala kvaliteta rubova komprimiranih slika s obzirom da su rubovi najvažniji dio za vizualni dojam kod čovjeka. Prikazana je usporedba $i$ značajna prednost CVQ u odnosu na VQ u smislu smanjenja vremena kodiranja slika mrežnica, a time je istaknuta i nova važna primjena CVQ.

\section{KLUUČNE RIJEČI}

prepoznavanje mrežnice; pomorska sigurnost; vektorska kvantizacija s klasifikacijom;

\section{REFERENCES}

[1] Jain AK, Flynn P, Ross A. Handbook of Biometrics. New York: Springer; 2007.

[2] Daugman J. How iris recognition works. IEEE Transactions on Circuits and Systems for Video Technology. 2004 Jan;14(1):21-30.

[3] Chapman W, Hicklin A, Kiebuzinski G, Komarinski P, Mayer-Splain J, Taylor M, Wallner R. Latent Interoperability Transmission Specification. National Institute of Standards and Technology. U.S. Department of Commerce; 2013 Jan. 46 p. NIST Special Publication 1152.

[4] Stephanie Young LT.Securing our borders: Biometrics at sea. Coast Guard Compass: Official blog of the U.S. Coast Guard. 2011 Nov 21[cited 2014 Nov 10]. Available from: http://coastguard.dodlive.mil/2011/11/securing-our-borders-biometrics-at-sea/

[5] Ives RW, Bishop DA, Du Y, Belcher C. Iris recognition: The consequences of image compression. EURASIP Journal on Advances in Signal Processing. 2010 Feb; 2010 (Article No. 24).

[6] Daugman J, Downing C. Effect of severe image compression on iris recognition performance. Information Forensics and Security, IEEE Transactions on. 2008 Mar;3(1):52-61.

[7] Kekre HB, Sarode TK, Bharadi VA, Abhishek AA, Arora RJ, Nair MC. Performance Comparison of DCT and VQ Based Techniques for Iris Recognition. Journal Of Electronic Science And Technology. 2010 Sep;8(3):223229.

[8] Čorić M, Gudelj A. Application of the vector quantization compression method in the video supervision of maritime systems. Paper presented at: 6th International maritime science conference; 2014 April 28-29; Solin, Croatia.

[9] Chen WH, Smith $\mathrm{CH}$, Fralick SC. Discrete Cosine Transform. IEEE Transactions on Computers. 1974 Jan;23(1):90-93.

[10] Laurin, A. Networked Video Surveillance and Compression Technology [Internet]. 2002 [updated 2002 Jun, cited 2014 Oct 11]. Available from: http://www.axis.com/documentation/whitepaper/video/video_compression_article.pdf

[11] V. Bhaskaran, K. Konstantinides. Image and video compression standards: algorithms and arhitectures. 2nd ed. SAD, Norwell, Massachusetts: Kluwer Academic Publishers; 1997.

[12] Ramamurthi B, Gersho A. Classified vector quantization of images. Communications, IEEE Transactions on. 1986 Nov;34(11):1105-1115.

[13] Quweider MK, Salari E. Efficient classification and codebook design for CVQ. IEE Proceedings-Vision, Image and Signal Processing. 1996 Dec;143(6):344352.

[14] McLaren SR. Reliability of iris recognition as a means of identity verification and future impact on transportation worker identification credential [PhD thesis]. California, Monterey: Naval Postgraduate School; 2008. 
[15] Daugman, J. The importance of being random: statistical principles of iris recognition. Pattern recognition. 2003;36(2):279-291.

[16] Guo G, Jones M, Beardsley P. A system for automatic iris capturing. Massachusetts: Mitsubishi Electric Research Laboratories; 2005 Jun. 10 p. Report No.: TR2005-044.

[17] Von Seelen UMC, Camus T, Venetianer PL, Zhang GG, Salganicoff M, Negin M. Active vision as an enabling technology for user-friendly iris identification. 2nd IEEE workshop on automatic identification advanced technologies; 1999. p. 169-172.

[18] USA Government Accounting Office. Transportation Security: TSA Has Made Progress in Implementing the Transportation Workers Identification Credential Program, but Challenges Remain. Washington: U.S. Government Accountability Office; 2007 Apr. Report No.: GAO-07-681T.

[19] Phoenix iris database. Available from: https://docs. google.com/file/d/OB_xRqfOMgQDGNIpIRHFuam8zbTg/edit?pli=1
[20] Linde Y, Buzo A, Gray RM. An Algorithm for Vector Quantizer Design. Communications IEEE Transactions on. 1980 Jan;28(1):84-95.

[21] Wikipedia - Mean squared error [Internet]. Wikipedia. 2013 [updated 2014 Oct 13, cited 2014 Dec 11]. Available from: http://en.wikipedia.org/wiki/Mean_ squared_error

[22] Haskell BG, Hang HM. Comparison of discrete cosine transform and vector quantization of medical imagery. Application of Optical Instrumentation in Medicine XIV and Picture Archiving and Communication Systems; 1986 Feb 02; Newport Beach, California. International Society for Optics and Photonics; 1986. p. 399-409.

[23] Ivanov, IA. Image Compression with Vector Quantization [Internet]. 2001 Apr 16 [cited 2015 Oct 18]. Available from: http://www.gamasutra.com/view/ feature/131499/image_compression_with_vector_. php?print=1 